\title{
The MD and MS degrees in Britain
}

\author{
I C McManus
}

Abstract

Higher medical degrees-MD and MS — have been awarded at an increased rate since 1980 , owing partly to increased numbers of medical graduates and partly to greater career competition. The pass rate has not changed since 1965. Regulations at various universities show substantial differences, particularly in the use of viva voce examinations for failed candidates, in permissible subject matter, and in allowing the submission of previously published papers.

As these degrees are important for careers, and are registrable by the General Medical Council, it is suggested that it should issue minimal standards to be observed by all universities.

\section{Introduction}

The higher medical degrees of Doctor of Medicine (MD; DM) and Master of Surgery (MS; MCh; ChM; MChir) have been long established. For instance, candidates have been admitted to the Cambridge MD degree for over 500 years. ' In recent years an apparently greater number of doctors have been taking them, owing in large part to greater competition for specialist hospital appointments. At the same time about one fifth of medical graduates ${ }^{2}$ have preferred instead to take the degree of Doctor of Philosophy (PhD), ${ }^{3}$ which is now often perceived to be of higher academic status (although this has not always been the case $^{4}$ ) since typically it differs from the MD and MS in requiring registration for a fixed term, usually three years, before submission and is always examined by viva voce examination. In addition, the $\mathrm{PhD}$ can be submitted in any academic subject that is taught in the university, and candidates need not have attained their

Department of Psychiatry, St Mary's Hospital Medical School, London W2 1NY IC McManus, MD, lecturer in psychology applied to medicine medical degrees at the university at which they wish to study for the $\mathrm{PhD}$. It is also apparently more enjoyable. ${ }^{5}$ The advantages of the MD and MS degrees are that a candidate often need not have registered in

TABLE I-Numbers of MD and MS degrees awarded each year

\begin{tabular}{|c|c|c|c|c|c|}
\hline & \multicolumn{5}{|c|}{ Year awarded } \\
\hline & 1985 & 1980 & 1975 & 1970 & 1965 \\
\hline \multirow{2}{*}{$\begin{array}{l}\text { No of MDs awarded by universities } \\
\text { No of universities giving information } \\
\text { Proportion of UK graduates produced by } \\
\text { responding universities }\end{array}$} & $\begin{array}{r}215 \\
17\end{array}$ & $\begin{array}{r}150 \\
17\end{array}$ & $\begin{array}{r}139 \\
15\end{array}$ & $\begin{array}{l}79 \\
12\end{array}$ & $\begin{array}{l}72 \\
10\end{array}$ \\
\hline & 0.947 & 0.947 & 0.891 & 0.493 & $0 \cdot 410$ \\
\hline Total estimated No of MDs awarded in UK & 227 & 158 & 156 & 160 & 175 \\
\hline No of MSs awarded by responding universities & 33 & 22 & 12 & 2 & 4 \\
\hline Total estimated No of MSs awarded in UK & 35 & 23 & 13 & 4 & 10 \\
\hline $\begin{array}{l}\text { Total estimated No of higher medical degrees } \\
\text { in UK }\end{array}$ & 262 & 181 & 169 & 164 & 185 \\
\hline $\begin{array}{l}\text { Approximate No of UK medical graduates } \\
10 \text { years earlier }\end{array}$ & 2800 & 2500 & 2000 & 1800 & 1800 \\
\hline $\begin{array}{l}\text { Estimated percentage of graduates with higher } \\
\text { medical degrees }\end{array}$ & $9 \cdot 4$ & $7 \cdot 2$ & $8 \cdot 5$ & $9 \cdot 1$ & $10 \cdot 3$ \\
\hline
\end{tabular}

advance and need not be resident at the university where they wish to take it.

Candidates who fail these examinations are often aggrieved but unable to find information on the typical administration and conduct of the degree. This paper reports on a comparative review of the regulations for higher medical degrees in British medical schools and an assessment of the numbers of people taking such degrees, particularly in order to examine changes during the past two decades either in number of awards or in pass rates.

\section{Method and results}

In the summer of 1986 a short questionnaire (two sides of A4 paper) was sent to the academic registrar of each of the 19 British universities that award first degrees in medicine, all of which also award higher medical degrees. Eighteen universities replied to the questionnaire, two could not provide information on numbers of graduates, and one refused to answer the questions. Where possible regulations for examinations were also obtained. It was possible to collect statistics on the numbers of degrees awarded at the university that refused to take part by visiting the university library.

Table I summarises the numbers of higher medical and surgical degrees (referred to as the MD and MS in this paper) awarded at the universities in the survey. Not all universities could provide information for each of the years in question, and table I shows the number of universities for which information was available and the proportion of medical graduates accounted for by those universities, allowing estimates of the total number of degrees awarded each year. Clearly the total number of degrees awarded increased substantially between 1980 and 1985. But the total number of medical graduates also increased during the same period, and table I gives an estimate of the numbers 10 years before higher degrees were awarded. Higher degrees are not awarded in any one year to a single cohort of graduates but to a fairly wide spread since theses are sometimes submitted 20 or 30 years after graduation. A typical interval between graduation and submission is about 10 years, ${ }^{367}$ and therefore corrections for increasing numbers of graduates are only rough. Nevertheless it seems that more degrees were awarded in 1985 than would be expected given the numbers awarded in 1980 .

Success rates-Several universities gave information on the number of theses submitted as well as of degrees awarded. Table II shows that for both the MD and MS degree the success rate remained almost constant during 1965-85 and that the success rate in the MD degree $(76.5 \%)$ is almost identical to that in the MS degree $(75 \cdot 6 \%)$. A complete calculation of success rates should also take into account that at least one fifth of theses are started but never submitted. ${ }^{5}$

Oral examinations-In 15 universities that provided information the percentage of candidates given viva 


\begin{tabular}{lccccc}
\hline & \multicolumn{5}{c}{ Year awarded } \\
\cline { 2 - 6 } & 1985 & 1980 & 1975 & 1970 & 1965 \\
\hline No of universities giving information on submission rates & 12 & 12 & 10 & 6 & 5 \\
No of MD theses submitted & 224 & 168 & 142 & 63 & 57 \\
No of MD degrees awarded at same universities & 178 & 118 & 113 & 48 & 43 \\
Success rate for MDs (\%) & $79 \cdot 5$ & $70 \cdot 2$ & $79 \cdot 6$ & $76 \cdot 2$ & $75 \cdot 4$ \\
No of MS theses submitted & 34 & 24 & 22 & 2 & 4 \\
No of MS degrees awarded at same universities & 28 & 19 & 12 & 2 & 4 \\
Success rate for MSs (\%) & $82 \cdot 4$ & $79 \cdot 2$ & $54 \cdot 5$ & 100 & 100 \\
Success rate overall (\%) & $79 \cdot 8$ & $71 \cdot 4$ & $76 \cdot 2$ & $76 \cdot 9$ & $77 \cdot 0$ \\
& & & & &
\end{tabular}

voce examinations was $100,100,90,75,75,25,20,15$, $10,5,<5,<1,0,0$, and 0 ; the proportion in the past 10 years was described as increased in two, decreased in two, and unchanged in the rest. Among candidates failing the examination the percentage that sat a viva was $100,100,100,100,100,100,100,75$, "most," "usual," $50,0,0,0$, and 0 .

Resubmission after failure-This is usually allowed in 10 universities, sometimes allowed in five (typically at the discretion of the examiners), and is "unusual" or occurs "seldom" in two universities.

Registration-Advanced registration is required in 10 universities, whereas in eight universities registration is at the time of submission. The time between submission and notification of a result varied from five weeks to nine months, but was typically six months.

Time since qualification-Universities required candidates to have been medical graduates for a minimum time of $2,2,2,3,3,3,4,4,4,4,5,5,5,5$, and 7 years.

Examiners-There are two examiners in nine universities, three examiners in seven universities, and four examiners in two universities. In all universities at least one examiner is external, and in 10 it is usual for two examiners to be external. Several universities had an additional external examiner when a member of staff was the candidate. In 10 universities candidates who had not sat the viva were not informed of the names of their examiners, in none were they informed officially, and in seven they were informed unofficially or were told by the department. The questionnaire did not ask whether candidates who sat the viva were formally notified of the names of examiners before the oral examination.

Classification-In 10 universities MDs were classified using such terms as "honours," "distinction," or "commendation," or medals or prizes might be awarded, and in eight universities they were unclassified.

Subject matter-Regulations were generally vague, but four universities had "narrow" regulations stating that the thesis had to be relevant to "medicine or surgery," while the rest had broader regulations suggesting that subject matter had to be relevant to medicine, or medical science, or the curriculum for the degrees of medicine and surgery. In several schools it was reported that theses were "occasionally," "rarely," or "extremely rarely" rejected on subject matter, and in none of these was there a formal basis for appeal. In seven universities the MD or MS could be obtained by submitting published papers (sometimes with an integrating account), whereas in 11 universities the degree was awarded only on the submission of original work as a thesis. In no university is it now possible to take the MD or MS as a written examination.

The degree of $M S$-Although all universities used to award the MS, two of the new universities award the MD only, and four much older universities have discontinued the MS degree within the past 15 years. In general the regulations for the MS are closely similar to those for the $M D$, and often a single set of regulations suffices for both degrees. Nevertheless, several universities still require candidates for the MS to have practised in approved surgical posts, and several make specific restrictions on the content of the thesis, although such universities are in a minority. The degrees of MChOrth (Master of Orthopaedic Surgery) and MAO (Master of Obstetrics) are each still awarded by one university.

\section{Discussion}

Higher medical degrees are important and unusual qualifications as graduates in other university subjects are not usually able to submit research theses without supervision, without residence, and without paying supervision fees. The advantages of such a system are typified by the fictional Dr Manson in The Citadel, who from his South Wales practice was able to submit to the University of St Andrews his thesis on dust inhalation in pulmonary disease ${ }^{8}$ (although probably only about $4 \%$ of $M D$ theses are submitted from general practice $^{9}$ ).

The higher degrees of $\mathrm{MD}, \mathrm{MS}$, and $\mathrm{PhD}$ are as a result of increased competition often seen by candidates, particularly recent graduates, ${ }^{5}$ to be essential for applying for consultant posts in the major medical disciplines. Thus the number of degrees awarded has increased substantially since 1980 , both absolutely (owing to increased numbers of medical graduates) and proportionately (reflecting the needs of recent graduates who are in greater competition for prestigious posts). From the results of this study it is impossible to say whether higher degrees are being obtained sooner after primary qualification, although a comparison of the findings in published studies ${ }^{35-7}$ does not suggest obvious changes.

The form of examination differs fairly substantially among universities, which is of some consequence to candidates since in most cases they are compelled to take the degree at the university at which they took their first medical degree. (The only exception is those who become academic members of staff of another university.) Of particular concern is the variation in the use of the viva voce examination, even for candidates who fail the degree. Also, the variation in the regulations on permissible subject matter means that subjects that âre permissible in some universities would not be acceptable at others, particularly if concerned with non-traditional basic medical sciences, with the history of medicine, or with aspects of the administration or regulation of medicine as a professional activity. Although this is said by university registrars to be a rare problem, that is not supported by anecdotal evidence.

Fundamental questions of equity and justice suggest that if higher medical degrees are important to people in their careers then the degrees should be administered in equivalent fashion in different universities. The Committee of Vice-Chancellors and Principals (CVCP) has recently put forward guidelines for the regulation of the $\mathrm{PhD}$ degree, and other professional bodies have' subsequently supplemented and annotated those guidelines. ${ }^{10}$ Since the $M D$ and MS degrees are registrable secondary qualifications, it may be desirable for the General Medical Council to issue similar guidelines for admittance to the degrees of $M D$ and $M S$.

I thank the registrars of the universities who made this study possible by returning the questionnaires and Ms S A Maitlis for her help.

\footnotetext{
1 Edwards AWF, Hanka R. Writing and speaking in medicine. Br Med $\mathcal{J}$

1976;iv: 1387.
2 Tripp JH. Career planning with the MRCP (UK). $\mathcal{J} R$ Coll Physicians Lond 1986;20:95-8.
} 
3 Ogston D. Postgraduate medical degrees of the University of Aberdeen, 1931-1969. Scoul Med f 1970;15:297-301.

4 Hawkins C. Writing the MD thesis. BrMed f 1976;ii:1121-4.

5 Wood GM, Catford JC. Research post-MRCP. I R Coll Physicians Lond 1986;20:89-94.

6 Wilson GM. Degree of MD by thesis. British fournal of Medical Education 1966;1:58-61.

7 Whitfield AGW. Higher medical and surgical degrees of the University of

Birmingham. British fournal of Medical Education 1967;1:359-62.
8 Cronin AJ. The citadel. London: Gollancz, 1937.

Williams WO. MD by thesis from general practice. British fournal of Medical Education 1969;3:171-5.

10 British Psychological Society. Code of practice on the supervision, preparation and examination of doctoral theses in departments of psychology. Bulletin of the British Psychological Sociery 1987;40:250-4.

(Accepted 6 April 1988)

\section{Letter from Bombay}

\section{An unmitigated tragedy}

\section{Sunil K Pandya}

Sir Jamsetjee Jejeebhoy Hospital-J J Hospital-was founded in 1845 and was soon acclaimed. Associated with the Grant Medical College, it is the oldest teaching institute in western and central India. The following account would have made the first Indian baronet, Sir Robert Grant, Dr Charles Morehead, and the others who led the institutions to glory hang their heads in shame.

"In January 1986 tragedy struck [patients in] the J J Hospital. . . . It started with Bapu Thombre. He died on 21 January. He was followed by 13 others. The last was Dawood Dholakia on 7 February . . . they all died unnatural and untimely deaths. Their ages ranged from 10 to 76 . Two of them were well on their way to recovery . . . they too died. The common drug administered to all 14 was glycerine. . . .

"But this glycerine was not harmless. It was lethal. It was contaminated with diethylene glycol, a deadly poison. As a result, all these patients developed anuria leading to renal cortical necrosis. It was irreversible. Dialysis was of no avail. They did not ask to be born; they did not choose to die. They died. They died as they had lived, quietly and in poverty.

"Little could they know that by their deaths they would arouse an outcry of public indignation which would lay bare lack of probity in public life, malaise and corruption in places high and low indulged in contempt of the laws of God and man.

"All is over bar the shouting. It is time to pause and forage into the murky water of lies, deceit, intrigue, ineptitude and corruption to salvage the truth about what led to this ghastly and tragical episode.

"To that end ... hereunder . . . the sequence of events."

The 289 page report that follows, again in the words of Justice Lentin, describes "the ugly facets of the human mind and human nature, projecting errors of judgment, misuse of ministerial power and authority, apathy towards human life, corruption, nexus and quid pro quo between unscrupulous . . . analytical laboratories, elements . . . controlling the awarding of rate contracts, manufacturers, traders, merchants, suppliers, the FDA and persons holding ministerial rank. None of this will be palatable in the affected quarters. But that cannot be helped."

\section{A rising toll}

Four of the fourteen who died had brain tumours. Three were receiving treatment for head injury. One had a cerebral stroke. Three had glaucoma, two cataracts, one iridocyclitis. One had undergone keratoplasty.

Vomiting; diarrhoea; gastrointestinal bleeding; abdominal pain, guarding, rigidity, and distension set in within four to five days of the administration of the

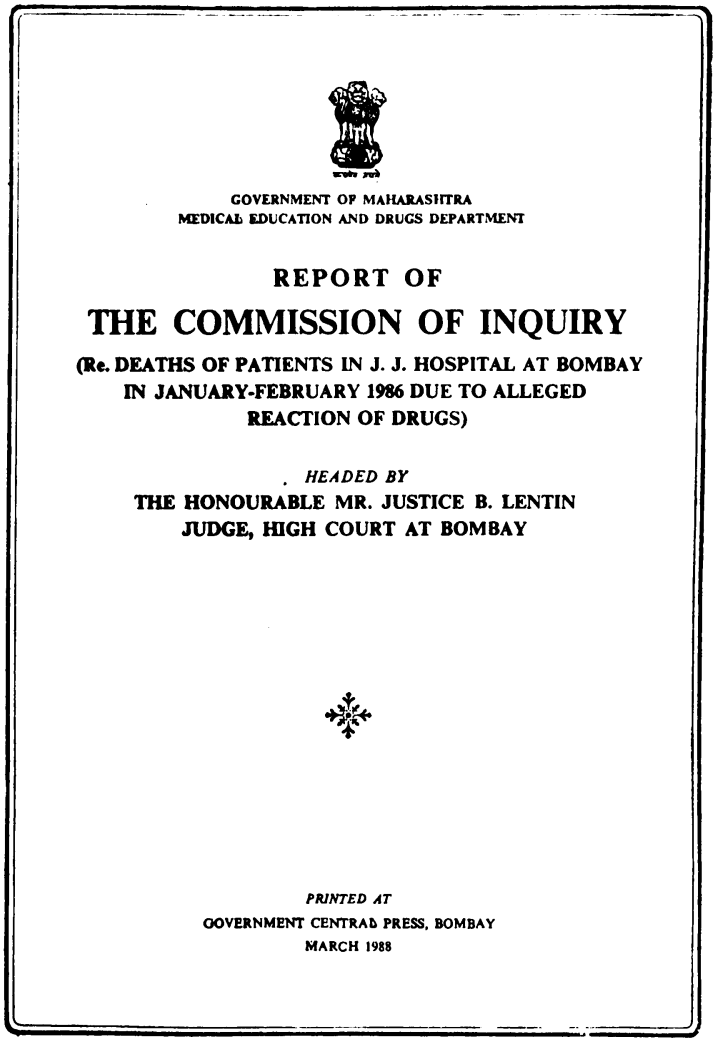

toxic glycerin. Over a further two to three days oliguria, anuria, acidosis, and instability of blood pressure followed.

The infusion of sodium bicarbonate, administration of acetazolamide, mannitol, and frusemide and the use of dialysis (in 12) were of no help. The first patient, Bapu Thombre, had been admitted to the general surgery ward on 15 January 1986 after a head injury. The next day he was transferred to the neurosurgical ward. On 20 January he developed anuria and despite the administration of mannitol and frusemide-on the advice of a nephrologist-died on 22 January. By 24 January seven patients who were developig anuria on neurosurgery, neurology and ophthalmology wards had been referred to the nephrology unit. Two of these seven died. By 27 January the number of patients with such anuria had risen to 11 .

There was nothing in the natural course of the diseases afflicting these patients to explain renal failure. The neurosurgeons and nephrologists were thus forced to consider the possibility of drug toxicity. Acetazolamide, mannitol, gentamicin, and glycerol, being the drugs common to the treatment given to all these patients, were withdrawn from use on 25 January. 